\title{
Molecular Dynamics Simulation Study for Ionic Strength Dependence of RNA-host factor Interaction in Staphylococcus aureus Hfq
}

\author{
Prettina Lazar, Yuno Lee, Songmi Kim, Meganathan Chandrasekaran, and Keun Woo Lee*
}

\author{
Division of Applied Life Science (BK21 Program), Environmental Biotechnology National Core Research Center (EB-NCRC), \\ Plant Molecular Biology and Biotechnology Research Center (PMBBRC), Gyeongsang National University (GNU), \\ 900 Gazwa-dong, Jinju 660-701, Korea.*E-mail: kwlee@gnu.ac.kr \\ Received December 1, 2009, Accepted April 7, 2010
}

\begin{abstract}
The behavior of peptide or protein solutes in saline aqueous solution is a fundamental topic in physical chemistry. Addition of ions can strongly alter the thermodynamic and physical properties of peptide molecules in solution. In order to study the effects of added ionic salts on protein conformation and dynamics, we have used the molecular dynamics (MD) simulations to investigate the behavior of Staphylococcus aureus Hfq protein under two different ionic concentrations: $0.1 \mathrm{M} \mathrm{NaCl}$ and $1.0 \mathrm{M} \mathrm{NaCl}$ in presence and absence of RNA (a hepta-oligoribonucleotide AU5G). Hfq, a global regulator of gene expression is highly conserved and abundant RNA-binding protein. It is already reported that in vivo the increase of ionic strength results in a drastic reduction of Hfq affinity for Q $\beta$ RNA and reduces the tendency of aggregation of Escherichia coli host factor hexamers. Our results revealed the crucial role of $0.1 \mathrm{M} \mathrm{NaCl} \mathrm{Hfq} \mathrm{system} \mathrm{on} \mathrm{the} \mathrm{bases} \mathrm{with} \mathrm{strong} \mathrm{hydrogen} \mathrm{bonding} \mathrm{interactions} \mathrm{and} \mathrm{by} \mathrm{stabilizing} \mathrm{the}$ aromatic stacking of Tyr42 residue of the adjacent subunits/monomers with the adenine and uridine nucleobases. An increase in RNA pore diameter and weakened compactness of the Hfq-RNA complex was clearly observed in $1.0 \mathrm{M}$ $\mathrm{NaCl} \mathrm{Hfq}$ system with bound RNA. Aggregation of monomers in Hfq and the interaction of Hfq with RNA are greatly affected due to the presence of high ionic strength. Higher the ionic concentration, weaker is the aggregation and interaction. Our results were compatible with the experimental data and this is the first theoretical report for the experimental study done in 1980 by Uhlenbeck group for the present system.
\end{abstract}

Key Words: Host factor protein-Hfq, Oligoribonucleotide, Post-transcriptional regulation, Molecular dynamics simulation, Ionic concentration

\section{Introduction}

Hfq is host factor protein which binds to Q $\beta$ RNA in Escherichia coli $(E$. coli). It is highly conserved, abundant and appears to function as a global regulator of gene expression. ${ }^{1}$ It plays an important role in the post-transcriptional regulation of $\mathrm{mRNAs}$ by facilitating pairing of noncoding RNA (ncRNAs) to mRNA target sites. The observed wide-spread use of Hfq in RNA metabolic processes is underscored by the finding that 22 sRNAs of $E$. coli bind $\mathrm{Hfq}$, to carry out their cellular functions through antisense recognition of target mRNAs. ${ }^{2}$ The simplest model for the interaction of the host factor hexamer with oligo's is that the binding site on the protein has a circular geometry and has dimensions such that it can accommodate a stretch of RNA 7 nucleotides long in this case study. The structure of the Staphylococcus aureus (S. aureus) Hfq in complex with the heptaoligoribonucleotide, $\mathrm{AU}_{5} \mathrm{G}$ (PDB ID: $\left.1 \mathrm{KQ} 2\right)$, has provided initial information on how uridine-rich stretches bind, as well as information on one mechanism of adenosine binding and how RNA can interact with riboregulator (Figure 1). ${ }^{3}$ Our recent mutation study on this $S$. aureus Hfa protein with bound RNA revealed the crucial role of residues far from the nucleotide binding portion affecting the monomer aggregation as well as the Hfq-RNA interaction, which provided a direction to proceed (a)

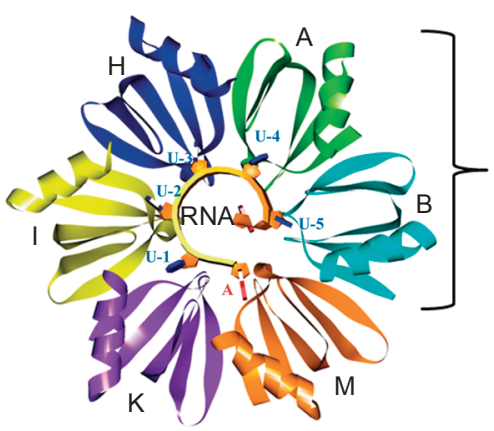

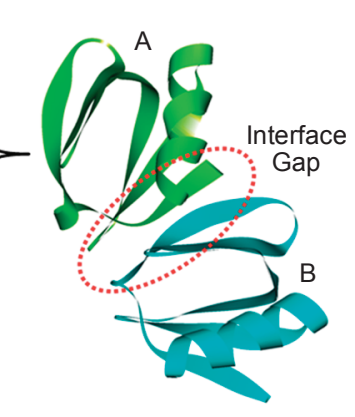

(b)

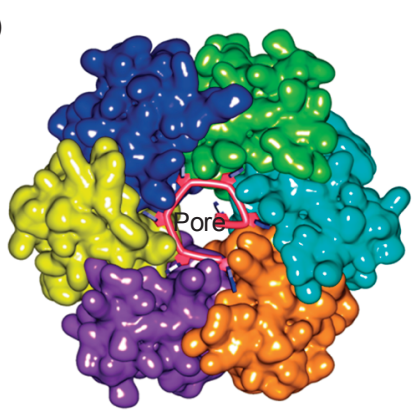

Figure 1. Crystal structure of S. aureus Hfq chains and bound RNA. (a) Secondary structure representation of Hfq in ribbon model, showing each chain in different colors with the bound $\mathrm{RNA}\left(\mathrm{AU}_{5} \mathrm{G}\right)$ shown as the backbone in the arrow model along with bases in the ring model emphasizing the interface gap region between monomer A and B as red lines. (b) Surface representation of the Hfq with the well-stacked RNA along the Hfq pore site. 
in analyzing the structure function relationship of the important sRNA- and mRNA-binding proteins focusing on some of the key residues far from the NBP of Hfq apart from the already known residues. ${ }^{4}$

Behavior of peptide in saline aqueous solution is a fundamental topic in physical chemistry. The interactions between water molecules and dissolved ions are of crucial importance for many physical and chemical processes in biological systems, in the atmosphere, and in technological applications. Addition of ions can strongly alter the thermodynamic and physical properties of peptide molecules in solution. The influence of salt on the conformation and physical properties of biomolecules in solution is an essential factor which is often overlooked in the analysis of structure-activity relationships and very little is known about the stabilizing or destabilizing interactions. There are several properties that characterize the behavior of water and protein in the presence of ions. These can be separated into structural and dynamical properties. ${ }^{5}$ Experimental report has already proven that increase in ionic strength results in a drastic reduction of the affinity of host factor for Q $\beta$ RNA and added salt greatly reduces the tendency of $E$. coli host factor hexamers to be aggregate. ${ }^{6}$ Aggregation observed at the low ionic strength i.e., $0.1 \mathrm{M}$ is involved in the tight binding of host factor to $\mathrm{Q} \beta$ RNA. 0.1 M solution is the biologically relevant condition needed by the Hfq protein to function properly in terms of monomer aggregation of the hexamers as well as affinity towards Q $\beta$ RNA. We used molecular dynamics (MD) simulation method to quantitatively study the conformational and interaction change of RNA binding in $S$. aureus Hfq protein under the two different ionic conditions, $0.1 \mathrm{M}$ and $1.0 \mathrm{M} \mathrm{NaCl}$ concentrations.

Computer experiments provide one of the most accepted routes to connect the microscopic model with the macroscopic behavior. The salting in and salting out of peptides in solution and the denaturing of protein are two very important effects, which have been investigated extensively by experiments. Sometimes, there is a slight increase in molecular volume of the protein, suggesting that salt makes the protein swell. In this study, the MD simulation method has been used to investigate the effect of structure making and structure-breaking capability of the $\mathrm{Na}^{+} / \mathrm{Cl}^{-}$ions, more precisely the influence of ionic salt concentration on the protein-RNA interaction in $S$. aureus HfqRNA conformation. Our results conclude and substantiate Uhlenbeck's experimental report that the biologically relevant condition of $0.1 \mathrm{M} \mathrm{NaCl}$ concentration is essential for the aggregation of monomers and $\mathrm{Q} \beta$ RNA affinity properties of Hfq protein. We believe that this study of ionic strength induced conformational changes will be helpful for understanding the structure-function relationship of the important RNA binding proteins in transcriptional activation and repression.

\section{Methods}

Computational details for molecular dynamics simulations. Molecular dynamics simulation has been extensively used to study the effect of various physio-chemical properties of biological molecules. For example study of self-diffusion coefficient and ionic mobility of $\mathrm{OH}^{-}$of the scaled OSS2 water model, ${ }^{7,8}$ effects of halothane on dimyristoylphosphatidylcho- line lipid bilayer structure, ${ }^{9}$ respectively are some of the well established biophysical properties determined using the MD simulation methodologies. Similarly, we have employed MD simulation study to explore the effect of different ionic strength on Hfq-RNA binding. The GROMACS package ${ }^{10,11}$ was used to perform MD simulations, while the protein and water molecules are described by parameters from AMBER99 $9^{12}$ and TIP $3 \mathrm{P}^{13}$ force fields, respectively. Hydrogen atoms were added and the protonation state of ionizable groups was chosen appropriate to $\mathrm{pH}$ 7.0. A solvent cubic box with length $12 \mathrm{~nm}$ was generated to perform the simulations in an aqueous environment. Six $\mathrm{Na}^{+}$ or $\mathrm{Cl}^{-}$counter-ions were added by replacing water molecules to ensure the overall charge neutrality of the simulated system. The electrostatic interactions were calculated by particle mesh Ewald (PME) summation and the non-bonded interactions were truncated at $9 \AA .{ }^{14}$ A constant temperature and pressure for the whole system ( $300 \mathrm{~K}$ and $1 \mathrm{bar}$ ) are achieved with the Berendsen thermostat $^{15}$ and Parrinello-Rahman ${ }^{16}$ barostat. The systems were subjected to the steepest descent energy minimization process with tolerance of $1000 \mathrm{~kJ} / \mathrm{mol}$. The time step for the simulations was set to $2 \mathrm{fs}$. During the system equilibration process the protein backbone was frozen and the solvent molecules with counterions were allowed to move during the $100 \mathrm{ps}$ under NPT conditions at $300 \mathrm{~K}$. The equilibrated structure was then used for the following $3 \mathrm{~ns}$ production runs. Bonds between heavy atoms and corresponding hydrogen atoms were constrained to their equilibrium bond lengths using the LINCS algorithm. ${ }^{17,18}$ During the production phase, the coordinate data were written to the file every pico second (ps).

Model structure setup for simulation. We considered six systems for our study using the $S$. aureus Hfq crystal structure (PDB ID: 1KQ2) ${ }^{3}$ in complex with the hepta-oligoribonucleotide, $\mathrm{AU}_{5} \mathrm{G}$ (Figure 1): native $\mathrm{Hfq}$ and $\mathrm{Hfq}$ under two different ionic concentrations $(0.1 \mathrm{M}$ and $1.0 \mathrm{M} \mathrm{NaCl})$ with/without RNA. Out of the six systems, two MD simulations of native $S$. aureus Hfq-RNA with explicit water molecules having $0 \mathrm{M} \mathrm{NaCl}$ concentration has been adopted from our previous study on the same protein for a comparative analysis with the present study. ${ }^{4}$ A detailed summary for the different model systems is listed in Table 1. In each system, the charge of the protein was neutralized by adding $\mathrm{Na}^{+} / \mathrm{Cl}^{-}$ions modulated by AMBER 99 and those systems were finally solvated with approximately 20500 TIP3P water molecules (Figure 2). In addition to the neutralizing ions, a $0.1 \mathrm{M} \mathrm{NaCl}$ salt concentration was established by

Table 1. System details for the six molecular dynamics simulations

\begin{tabular}{|c|c|c|c|c|c|c|}
\hline \multirow[t]{2}{*}{ No. } & \multirow[t]{2}{*}{ Name } & \multirow{2}{*}{$\begin{array}{c}\text { Total No. of } \\
\text { TIP3P Water } \\
\text { Molecules }\end{array}$} & \multicolumn{2}{|c|}{$\begin{array}{c}\text { Total No. of } \\
\text { Charge-Balancing } \\
\text { ions }\end{array}$} & \multicolumn{2}{|c|}{$\begin{array}{l}\text { Total No. of } \\
\text { Counter } \\
\text { ions }\end{array}$} \\
\hline & & & $\mathrm{Na}^{+}$ & $\mathrm{Cl}^{-}$ & $\mathrm{Na}^{+}$ & $\mathrm{Cl}^{-}$ \\
\hline & Hfq & 20551 & - & 6 & - & - \\
\hline 2 & Hfq-RNA & 20494 & - & - & - & - \\
\hline 3 & $0.1 \mathrm{M} \mathrm{Hfq}$ & 20414 & - & 6 & 40 & 46 \\
\hline 4 & $0.1 \mathrm{M}$ Hfq-RNA & 20471 & - & - & 40 & 40 \\
\hline 5 & $1.0 \mathrm{M} \mathrm{Hfq}$ & 19684 & - & 6 & 405 & 411 \\
\hline 6 & 1.0 M Hfq-RNA & 19741 & - & - & 405 & 405 \\
\hline
\end{tabular}


(a)

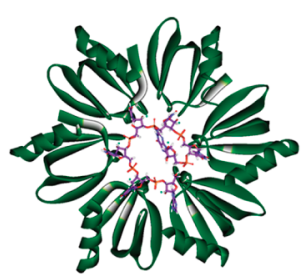

(c)

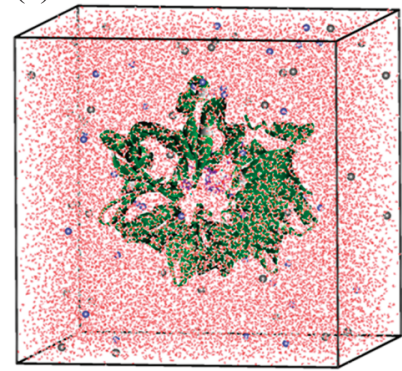

(d)

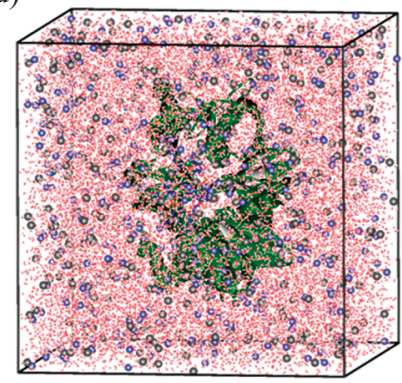

Figure 2. The Hfq-RNA complex modeled systems for the MD simulations. The complex is located without water box (a) and with the water box of $0 \mathrm{M} \mathrm{NaCl}$ (b), $0.1 \mathrm{M}$ (c), $1.0 \mathrm{M}$ (d) $\mathrm{NaCl}$ concentration. Proteins are shown as ribbon (green) model along with RNA and water molecules in stick model (colored by atom). $\mathrm{The} \mathrm{Na}^{+}$(grey) and $\mathrm{Cl}^{-}$(violet) ions are shown in CPK model.

adding 40 pairs of $\mathrm{Na}^{+} / \mathrm{Cl}^{-}$ions in the solvent box, and similarly (Figure $2 \mathrm{~b}$ ), a $1.0 \mathrm{M} \mathrm{NaCl}$ salt concentration was accomplished by the addition of 405 pairs of $\mathrm{Na}^{+} / \mathrm{Cl}^{-}$ions (Figure $2 \mathrm{c}$ ). The exact number of $\mathrm{Na}^{+} / \mathrm{Cl}^{-}$ions added to an explicit solvent to obtain the proper concentration was achieved by knowing the volume of the solution in the cubic box.

Interface gap analysis between Hfq monomers and Hfq-RNA using PROTROP. Changes in interface gap volume between Hfq monomers were observed using a protein-protein interface analysis server called PROTROP. ${ }^{19}$ The PROTORP server is a bioinformatics tool designed to analyze the interfaces between protein chains in protein-protein associations. The server takes input based on PDB (Protein Data Bank) formatted files. ${ }^{20}$ For the analysis of a protein interface, the PROTORP server incorporates a suite of analytical packages to calculate a set of physiochemical parameters exhibited by each protein interface. Various interface properties were calculated for the Hfq-RNA complex systems using only the monomers A and B as representative chains (Figure 1a).

\section{Results and Discussions}

Stability of the modeled Hfq systems under different ionic strengths. Earlier, Uhlenbenck et al. ${ }^{6}$ have reported that the increase of the salt concentration has drastic influence on the Hfq aggregate monomers and also on the interaction of RNA with Hfq. To address the experimental results, we introduce two Hfq model systems in different salt concentrations of $0.1 \mathrm{M}$ and 1.0 $\mathrm{M} \mathrm{NaCl}$ to observe the changes in monomer aggregation and RNA interactions with Hfq systems. During the simulation (a)

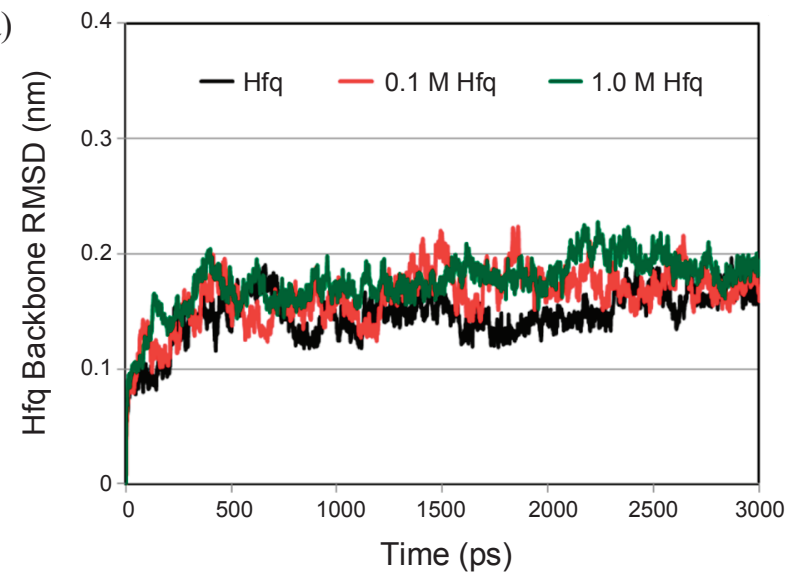

(b)

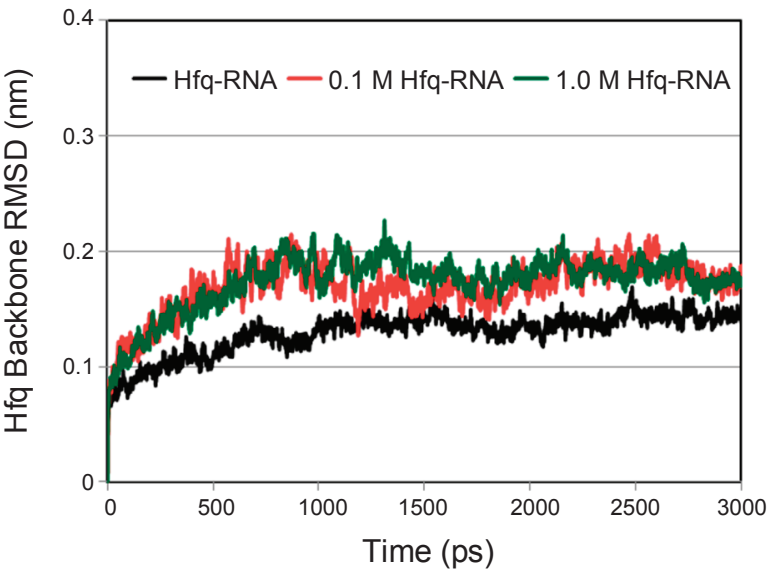

Figure 3. The root mean square deviation (RMSD) for the protein backbone atoms of Hfq systems during the simulation times (0 M $\mathrm{NaCl}, 0.1 \mathrm{M} \mathrm{NaCl}$ and $1.0 \mathrm{M} \mathrm{NaCl}$ concentrations, respectively) (a) without and (b) with bound RNA.

times, the root mean square deviation (RMSD) of the protein backbone atoms was analyzed to check the stability of the model systems. The backbone atom RMSD values of all the three Hfq systems are gradually increased until first 500ps for Hfq without bound RNA and then stabilized near to $0.2 \mathrm{~nm}$ (Figure 3 ). For the three Hfq-RNA complex systems, the RMSD values increased until first $1 \mathrm{~ns}$. Although minor difference was observed between the two systems, in overall all the six systems have been stabilized without any problems during the simulation times.

The RMSD of each chain (monomer) of the Hfq hexamer was also observed individually (Figure 4). The RMSD of all the monomers of $\mathrm{Hfq}$ with $0.1 \mathrm{M} \mathrm{NaCl}$ concentration without bound RNA system had gradually increased until 1 ns and stabilized at near $0.2 \mathrm{~nm}$ except the chain $\mathrm{M}$ which deviated drastically after $1 \mathrm{~ns}$ but stabilized towards the end of $3 \mathrm{~ns}$ (Figure 4c). A similar behavior was also observed in the Hfq $0 \mathrm{M} \mathrm{NaCl}$ concentration (Figure 4a). We noticed that the RMSD of Hfa gradually increased until 500ps, and stabilized for all chains, except for chain $M$ that had more than $0.2 \mathrm{~nm}$ deviations between 2 - 3 ns. There was no particular chain deviation observed in highly concentrated Hfq system (Figure 4e) and in the Hfq systems with bound RNA (Figure 4b, 4d \& 4f). Again it can be 
(a)

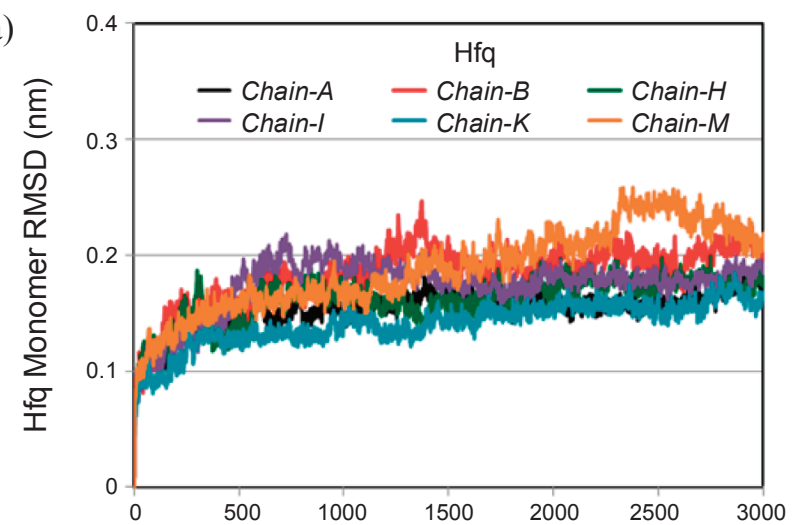

(c)

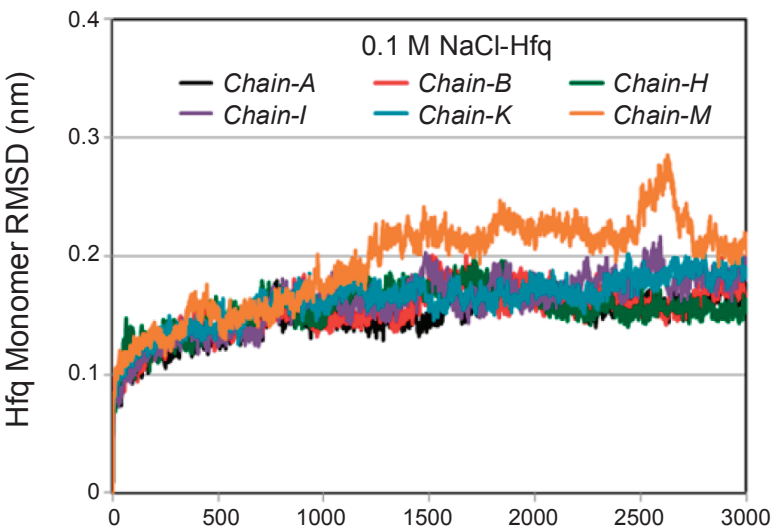

(e)

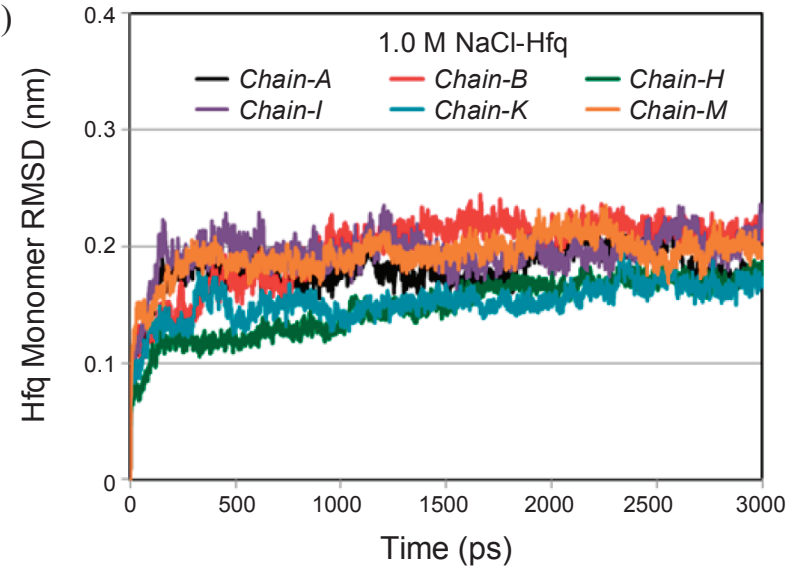

(b)

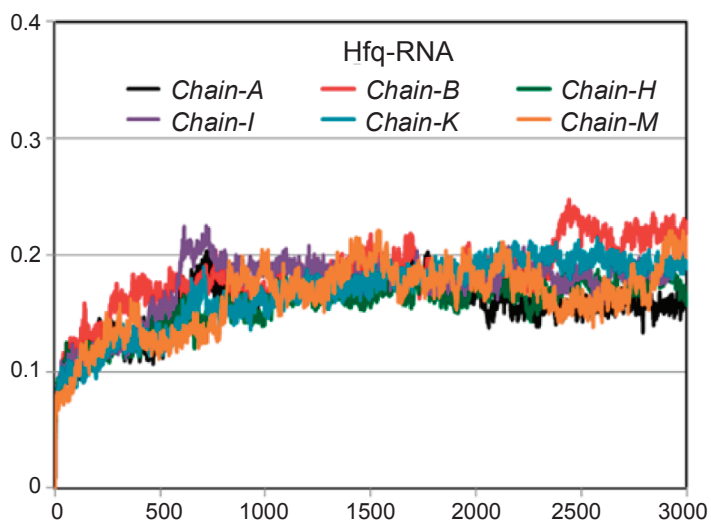

(d)

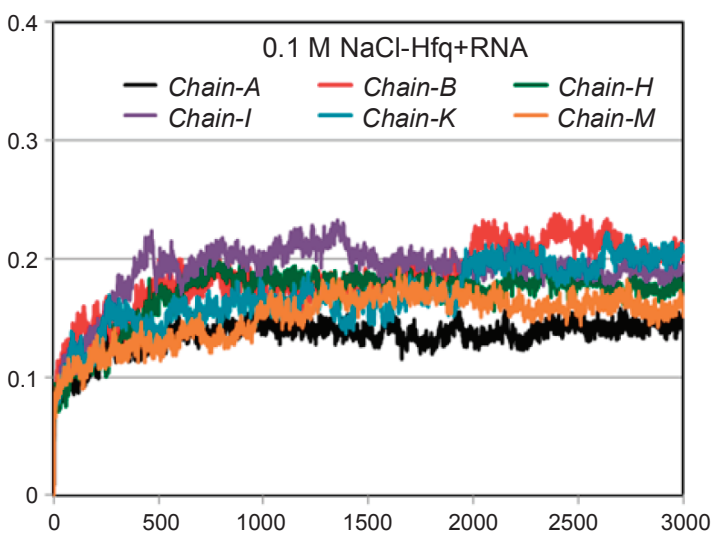

(f)

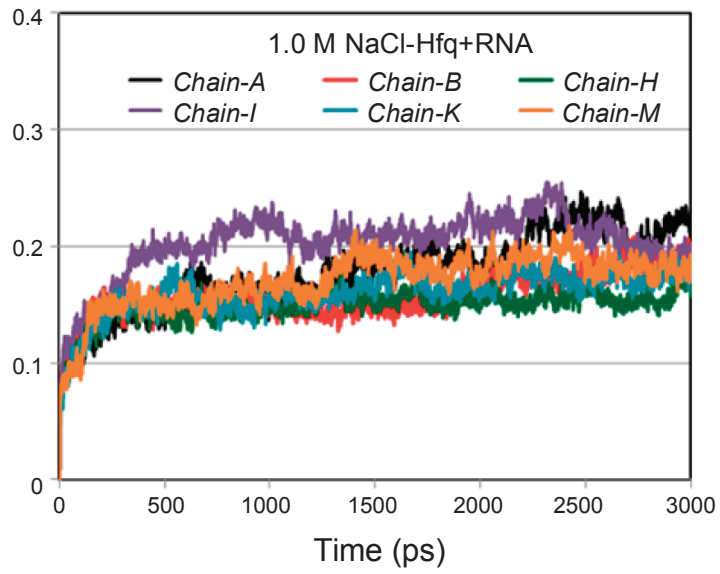

Figure 4. RMSD for the backbone atoms of each monomer chain of the Hfq hexamer during the simulation for (a) Hfq and (b) Hfq-RNA complex with $0 \mathrm{M} \mathrm{NaCl}$ concentration, (c) $\mathrm{Hfq}$ and (d) Hfq-RNA complex with $0.1 \mathrm{M} \mathrm{NaCl}$ concentration, (e) Hfq and (f) Hfq-RNA complex with $1.0 \mathrm{M} \mathrm{NaCl}$ concentration systems.

concluded that all the six chains have been well stabilized during the simulation times.

Influence of salt concentration on base stacking. The RMSDs of the seven bases of the RNA were also monitored to observe the movement of the bases during the simulation time (Figure 5). The results showed that the RMSD of the Hfq system with $0.1 \mathrm{M}$ $\mathrm{NaCl}$ concentration was significantly lower than other two systems (Figure 5b). It seems that the $0.1 \mathrm{M} \mathrm{NaCl}$ concentration makes the bases more stable in its stacked position in comparison to the $1.0 \mathrm{M} \mathrm{NaCl}$ system and the system with $0 \mathrm{M} \mathrm{NaCl}$ concentration. With the complex representative structures of each system, the distance between the center of mass of the Tyr42 of chain A and M were measured quantitatively to analyze the stacking behavior of Tyr42 residue. We were able to notice that in the Hfq system with 0 and $0.1 \mathrm{M} \mathrm{NaCl}$ concentration, the corresponding Tyr42 of the adjacent monomer subunits distance was $17.4 \AA$ and $16.6 \AA$ respectively, which gave stability to adenosine and uracil bases bound to $\mathrm{Hfq}$ (Figure $6 \mathrm{a}, 6 \mathrm{~b}$ ). Whereas in $\mathrm{Hfq}$ system with $1.0 \mathrm{M} \mathrm{NaCl}$ concentration, the distance calculated was about $22.8 \AA$ between the Tyr42 residues of the monomer subunits (A and $\mathrm{M}$ ), which clearly depicts that Tyr42 moved apart in high ionic concentration, leaving the 
(a)

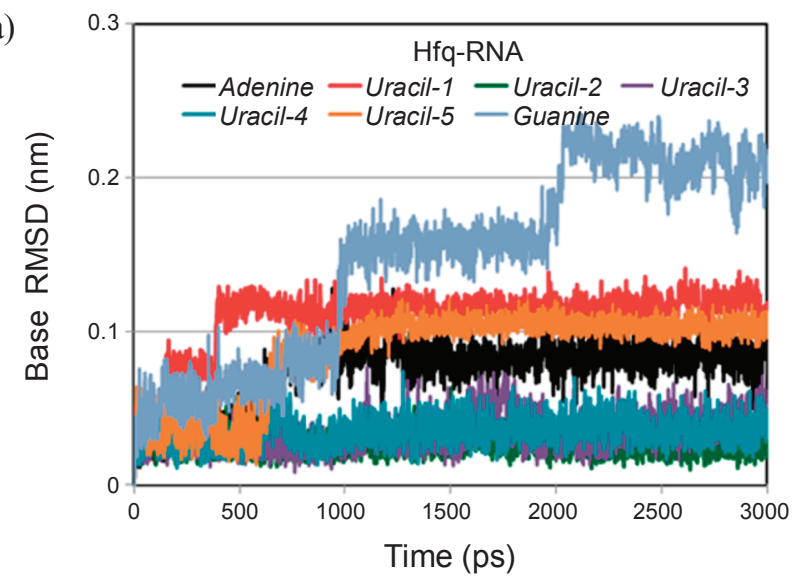

(b)

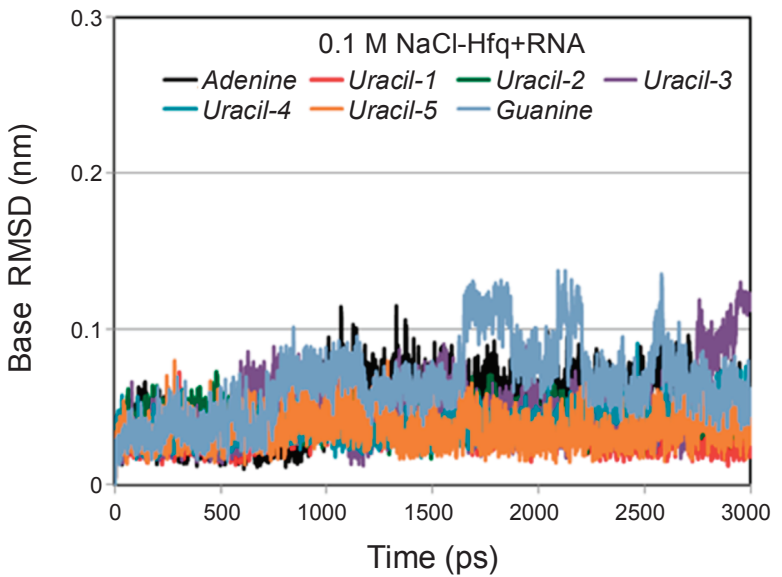

(c)

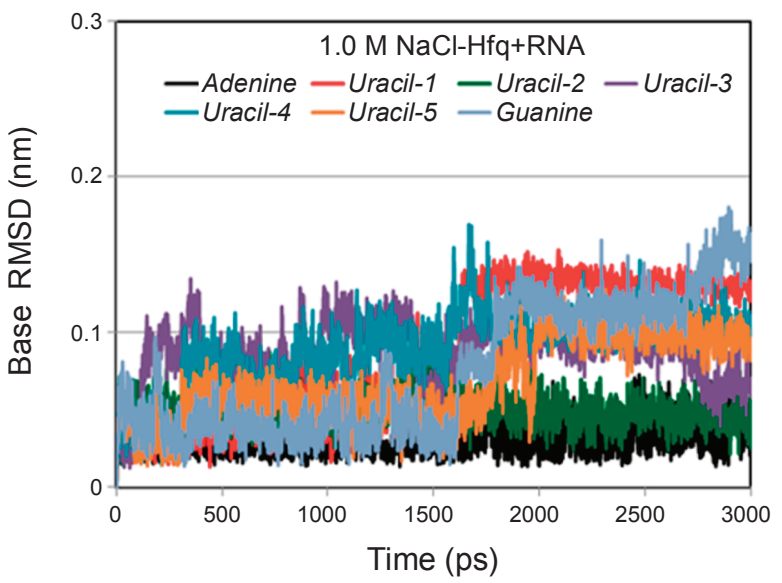

Figure 5. RMSD of each base of the ribonucleotide $\left(\mathrm{AU}_{5} \mathrm{G}\right)$ bound to Hfq during the simulation for Hfq-RNA complex with (a) $0 \mathrm{M} \mathrm{NaCl}$ (b) $0.1 \mathrm{M} \mathrm{NaCl}$ and (c) with $1.0 \mathrm{M} \mathrm{NaCl}$ concentrations, respectively.

bases unstable in its stacked position (Figure 6c). Hence, high ionic concentration seems to affect the stacking residue Tyr42 of the monomers, ${ }^{3}$ whose aromatic side chain has moved from its original position, which provided the stacking atmosphere for the adenine and uridine nucleobases.

Based on this observation, it can be interpreted as the base stability in the $0.1 \mathrm{M} \mathrm{NaCl}$ concentration is essential for the proper function of Hfq-RNA complex bound state for the pro- (a)

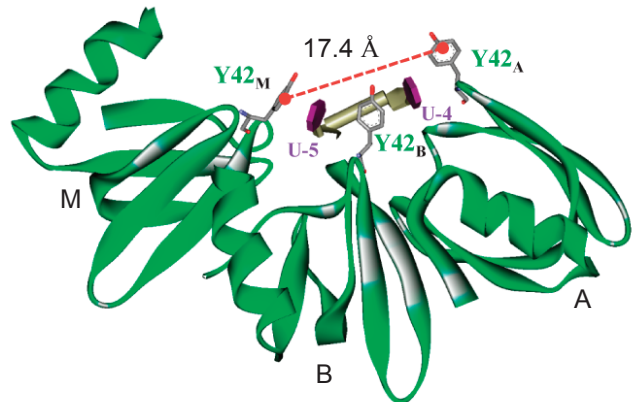

(b)

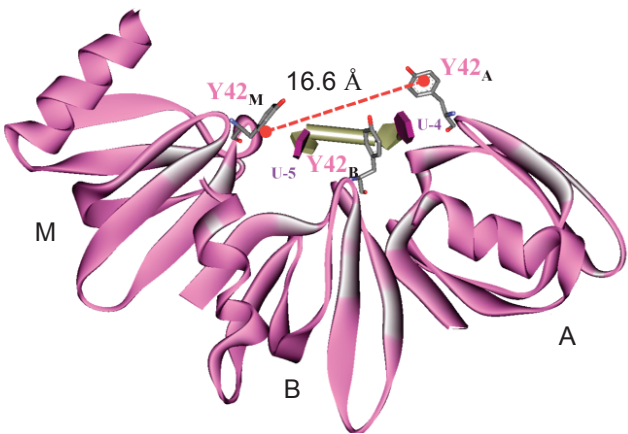

(c)

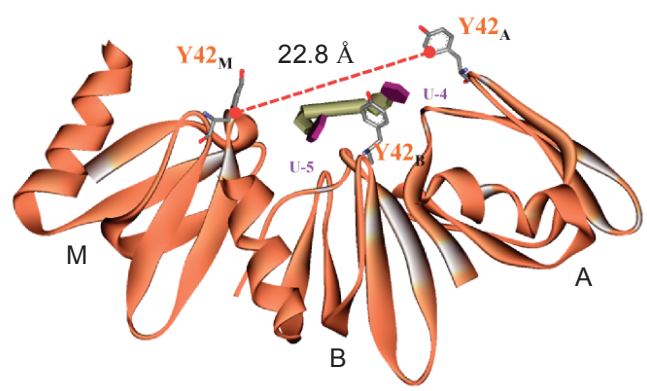

Figure 6. Distance analysis of the stacking residue Tyr42 in the monomer subunits (A and $\mathrm{M}$ ) of Hfq-RNA complexes with (a) $0 \mathrm{M} \mathrm{NaCl}$ (b) $0.1 \mathrm{M} \mathrm{NaCl}$ and (c) with $1.0 \mathrm{M} \mathrm{NaCl}$ concentrations, respectively. Representing only three chains (A, B and $\mathrm{M}$ ) in ribbon model and two bases (Uracil-4 and Uracil-5, ref. Figure 1) stacked to it with backbone in tube model and bases in ring form for clarity.

per function.

Influence of salt concentration on Hfq pore diameter. The Hfq pore diameter was examined, since a specific pore diameter is required for the threading of RNA through the pore for the post translational modification. The pore diameter was calculated by measuring the distance from the center of an atom of one of the pore lining residue of the highly conserved YKHAI motif of one chain to the same pore lining residue of the exactly opposite chain. Here to measure the pore diameter the two His58 residues in the YKHAI motif of the chain $\mathrm{A}$ and $\mathrm{K}$ were used. The pore diameter of the native Hfq-RNA complex with $0 \mathrm{M}$ $\mathrm{NaCl}$ concentration is between $1.2-1.4 \mathrm{~nm}$ (Figure 7b), but it gradually increased to $2 \mathrm{~nm}$ in the $1.0 \mathrm{M} \mathrm{NaCl} \mathrm{Hfq} \mathrm{system} \mathrm{with}$ bound RNA. No such increase in pore diameter was observed in the other systems. Hence it is inferred that in the presence of RNA when the ionic salt concentration is increased, the dual properties may enhance the post translational modification, 
(a)

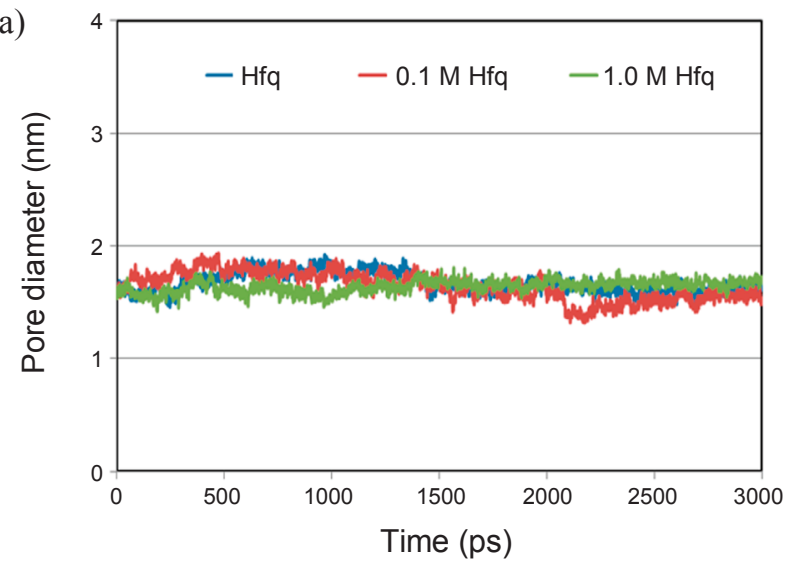

(b)

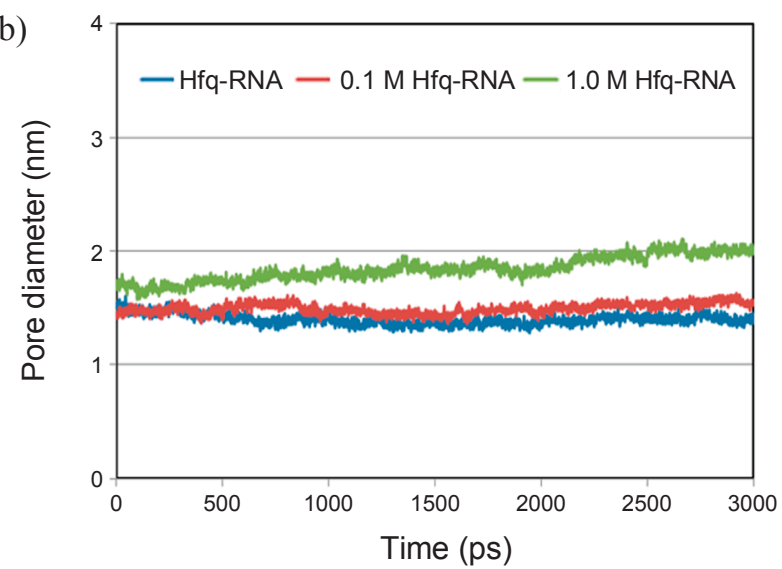

Figure 7. Time dependence change in Hfq pore diameter for the systems $(0 \mathrm{M}, 0.1 \mathrm{M} \mathrm{NaCl}$ and $1.0 \mathrm{M} \mathrm{NaCl}$ concentrations, respectively) averaged over the last $2 \mathrm{~ns}$ in the simulation time (a) without and (b) with bound RNA.

more specifically the assembly/remodeling of RNA-protein complexes and also threading of RNA through the pore by increasing its diameter. However, this increase in diameter may be due to weakening of the monomer arrangement in $\mathrm{Hfq}$ and hence affecting the compactness of the monomer to form the biologically active hexamer. In order to check this condition, the total compactness of the protein monomer to form the stable hexamer was monitored by measuring the radius of gyration of the complexes (Figure 8). The graph shows a clear disorder in the protein compactness due to increase in ionic salt concentration after $1 \mathrm{~ns}$ in the RNA bound Hfq system. Howerver, there is no such noticeable change observed in the Hfq systems without bound RNA. Hence we conclude that, the increase of ionic salt concentration weakened the compactness of protein by increasing the pore diameter. This in turn might have disrupted or broken the sixfold symmetry of the Hfq ring.

Influence of salt concentration on structural change. In order to observe the conformational changes in $\mathrm{C}_{\alpha}$ backbone of the two ionic salt concentration systems, the complex representative structures were obtained from the MD simulation trajectories and compared. The representative structures of the complex were picked from the most stable trajectories of the MD simulations. For our study we choose the last $2 \mathrm{~ns}$ trajectory frames and selected the one that had the lowest RMSD with the initial
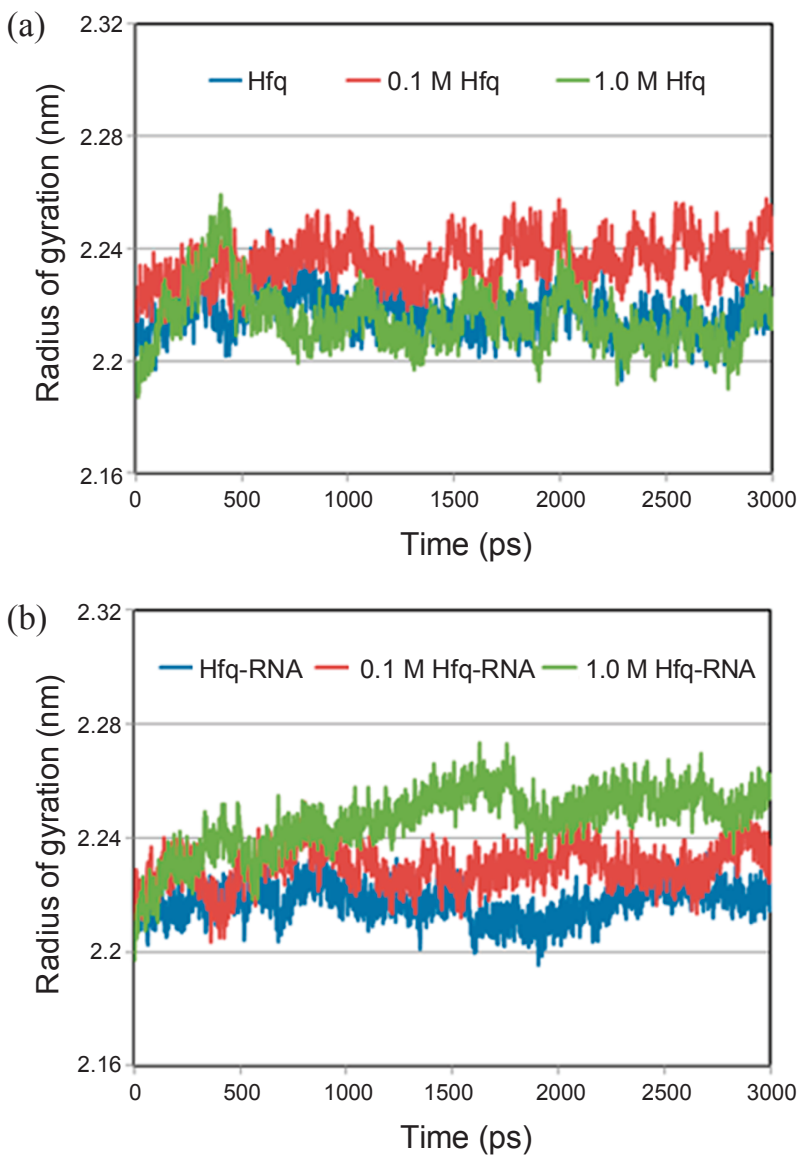

Figure 8. Radius of gyration during the simulation times for systems $(0 \mathrm{M} \mathrm{NaCl}, 0.1 \mathrm{M} \mathrm{NaCl}$ and $1.0 \mathrm{M} \mathrm{NaCl}$ concentrations, respectively) to monitor compactness of Hfq hexamer to maintain ring form in (a) without and (b) with bound RNA.

optimized complex structure using gromacs commands and pre-written in-house program for the purpose. The complex structure in $0 \mathrm{M} \mathrm{NaCl}$ concentration was superimposed with the structures in $0.1 \mathrm{M} \mathrm{NaCl}$ and $1.0 \mathrm{M} \mathrm{NaCl}$ concentrations, respectively (Figure 9). Relatively larger structural change was found in the $1.0 \mathrm{M} \mathrm{NaCl}$ case, especially in $\mathrm{A}, \mathrm{K}$, and $\mathrm{M}$ chains (Figure 9b). The RMSDs for the superimposed structures of $0 \mathrm{M}$ $\mathrm{NaCl}$ concentration with $0.1 \mathrm{M} \mathrm{NaCl}$ and $1.0 \mathrm{M} \mathrm{NaCl}$ were $1.66 \AA$ and $2.43 \AA$, respectively. The $\mathrm{C}_{\alpha}-\mathrm{C}_{\alpha}$ distances of the superimposed structures were also measured to obtain the detailed information about the deviation (Figure 9c). The plot definitely shows that the deviations in $1.0 \mathrm{M} \mathrm{NaCl}$ are some extent higher than that in $0.1 \mathrm{M} \mathrm{NaCl}$ concentration. This result also supports that the increasing ionic salt concentration induces the structural changes of our modeled Hfq-RNA complex systems.

Influence of salt concentration on the interaction between Hfq and RNA, and monomer aggregation. In order to study the influence of salt concentration for the interaction between Hfq and RNA, three properties were considered: 1) the number of hydrogen bonds between Hfq and RNA, 2) the volume of interface gap and 3) van der Waals interaction energy between two Hfq monomers. The number of hydrogen bonds between Hfq and RNA was averaged over the last $2 \mathrm{~ns}$ and the interface 
(a)

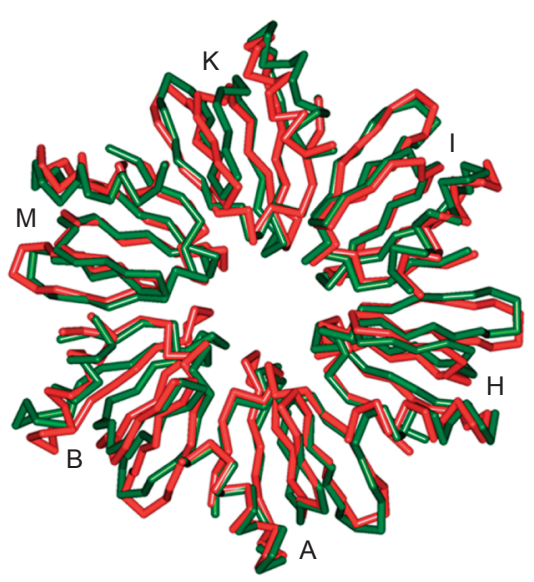

(b)
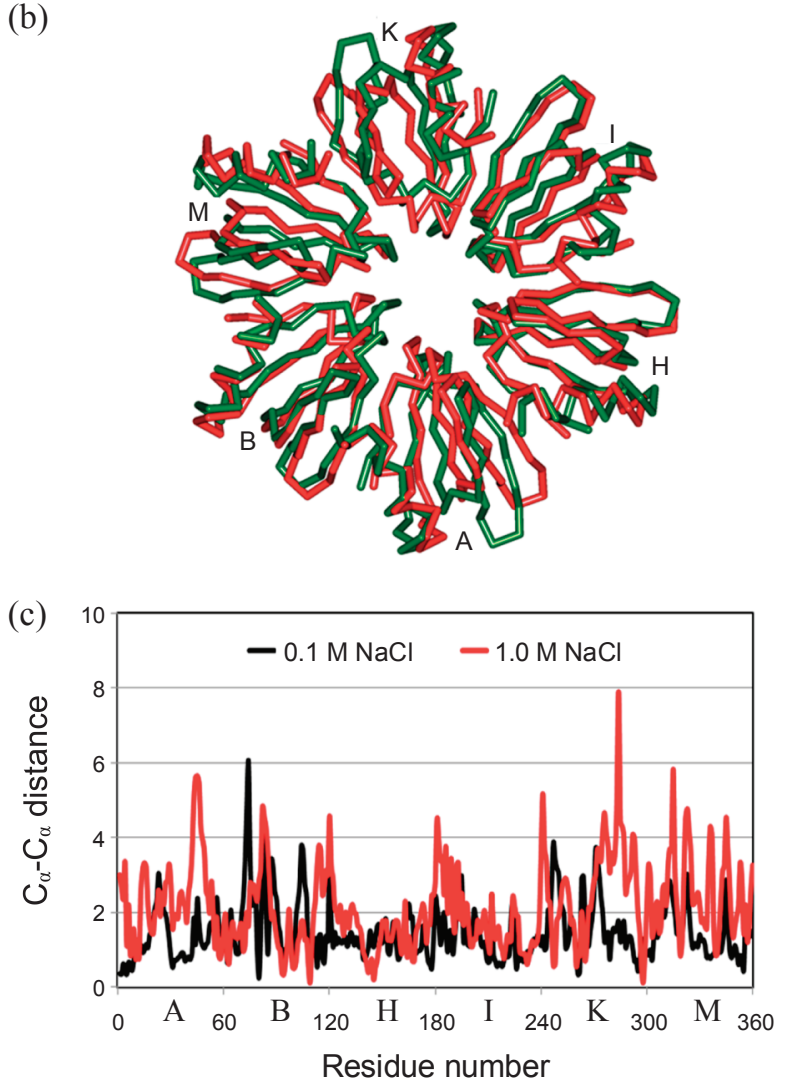

Figure 9. Comparison between the representative structures of the Hfq-RNA complex systems. The complex structure in $0 \mathrm{M} \mathrm{NaCl}$ concentration (red) was superimposed with the structures in (a) $0.1 \mathrm{M}$ $\mathrm{NaCl}$ and (b) $1.0 \mathrm{M} \mathrm{NaCl}$ concentrations, respectively in green $\mathrm{C}_{\alpha}$ backbone model. (c) Measured $\mathrm{C}_{\alpha}-\mathrm{C}_{\alpha}$ distances of the superimposed structures.

gap volume and van der Waals interaction energy were calculated between the two monomers of $\mathrm{A}$ and $\mathrm{B}$ of the Hfq hexamer (Table 2). Under the cellular ionic condition $(0.1 \mathrm{M} \mathrm{NaCl})$, the binding of a host factor to $\mathrm{Q} \beta \mathrm{RNA}$ is $50 \%$ more tighter than in the $1.0 \mathrm{M} \mathrm{NaCl} \mathrm{Hfq-RNA} \mathrm{system.} \mathrm{Our} \mathrm{results} \mathrm{for} \mathrm{the} \mathrm{number}$ of H-bonds show 13.39 and 8.54 for $0.1 \mathrm{M}$ and $1.0 \mathrm{M} \mathrm{NaCl}$ systems, respectively. This result strongly supports that the interaction between the $\mathrm{Hfq}$ and RNA in $0.1 \mathrm{M} \mathrm{NaCl}$ condition is much tighter than in the $1.0 \mathrm{M}$ concentration. Also the results
Table 2. Average numbers of hydrogen bonds between Hfq and RNA, the calculated interface gap volume and van der Waals energy between two monomers (A-B) of the Hfq-RNA complex for the three systems

\begin{tabular}{cccc}
\hline $\begin{array}{c}\text { Hfq-RNA } \\
\text { Complex } \\
\text { Systems }\end{array}$ & $\begin{array}{c}\text { Avg. No. of } \\
\text { H-bonds } \\
\text { Hfq-RNA }\end{array}$ & $\begin{array}{c}\text { Interface Gap } \\
\text { Volume between } \\
\text { A-B }\left(\AA^{3}\right)\end{array}$ & $\begin{array}{c}\text { van der Waals } \\
\text { Energy between } \\
\text { A-B }(\mathrm{kcal} / \mathrm{mol})\end{array}$ \\
\hline Hfq & 12.27 & 2203.88 & -111.173 \\
0.1 M Hfq & 13.39 & 2099.25 & -217.648 \\
1.0 M Hfq & 8.54 & 2494.12 & -90.052 \\
\hline
\end{tabular}

of the interface gap volume are compatible with this trend. At the high concentration of $1.0 \mathrm{M}$, the volume is significantly increased to $2494.12 \AA^{3}$ from $2099.25 \AA^{3}$ at the $0.1 \mathrm{M}$. The higher the gap volume between the monomers, the weaker is the aggregation between monomers. Finally, the average van der Waals interaction energy between the two monomers A and B show -217.648 and $-90.052 \mathrm{kcal} / \mathrm{mol}$ for $0.1 \mathrm{M}$ and $1.0 \mathrm{M}$ $\mathrm{NaCl}$ condition respectively. This clearly depicts that $0.1 \mathrm{M}$ $\mathrm{NaCl}$ condition gives a more favorable interaction between the monomers than the other two systems. Hence it can be inferred that the higher the salt concentration, the weaker the interaction between Hfq and RNA. The weaker interaction can be translated into lowering the aggregation between the monomers of the Hfq-RNA complex systems.

\section{Conclusions}

In this study, we explored the ionic salt concentration dependent structural disability and refolding in $S$. aureus Hfq protein. It was reported from an experiment about $E$. coli $\mathrm{Hfq}$ that the high ionic salt concentration destabilizes the protein by weakening the hexamer aggregation which affects the interaction between Hfq and RNA, and hence influences the function drastically. Here we used the MD simulation method to study the ionic salt effect on $S$. aureus Hfq, using two different ionic strength systems: $0.1 \mathrm{M} \mathrm{NaCl}$ and $1.0 \mathrm{M} \mathrm{NaCl}$, where former is the biologically relevant or cellular ionic salt concentration, later one is the extreme ionic salt concentration. Total six MD simulations were introduced with/without RNA to study the impact of high ionic salt concentration on protein aggregation and interaction with RNA.

The results revealed the crucial role of $0.1 \mathrm{M} \mathrm{NaCl} \mathrm{Hfq}$ system on the bases by stabilizing the aromatic stacking of Tyr 42 residue of the adjacent subunits/monomers with the adenine and uridine nucleobases. An increase in RNA pore diameter and the weakened compactness of the Hfq-RNA complex was clearly observed in the $1.0 \mathrm{M} \mathrm{NaCl} \mathrm{Hfq}$ system with bound RNA. The binding affinity was estimated by three physicochemical properties including the number of $\mathrm{H}$-bonds, interface gap volume, and averaged van der Waals interaction. All values from the results of those properties support that the interaction in $0.1 \mathrm{M} \mathrm{NaCl}$ case is stronger than the others. Structural comparison of each system also revealed a similar trend. Overall, a tighter binding of host factor to $\mathrm{Q} \beta \mathrm{RNA}$ and between the monomers of Hfq hexamer was found in the case of the cellular 
ionic condition $(0.1 \mathrm{M} \mathrm{NaCl})$ rather than the extremely higher concentration.

Our results from the MD simulation studies suggest that RNA binding influences the tendency of a host factor to aggregate. At the low ionic strength $(0.1 \mathrm{M} \mathrm{NaCl})$, the binding of $\mathrm{Q} \beta$ RNA is much stronger, while increasing ionic strength results in a drastic reduction of the binding affinity of a host factor for Q $\beta$ RNA. This substantiates the Uhlenbeck et al. ${ }^{6}$ experimental results. Finally, the aggregation phenomenon of the Hfq was challenged by our computational approaches and reasonably explained. There are no other theoretical studies based on MD simulation so far for the present system or $E$. coli for the study of ionic salt concentration. This paper is the first theoretical report for the experimental study obtained earlier in 1980 by Uhlenbeck group. This will be helpful for understanding the structure-function relationship of the important RNA binding proteins in transcriptional activation and repression based on salt concentration-dependent structural disability and refolding.

Acknowledgments. Prettina Lazar, Yuno Lee, Songmi Kim and Meganathan Chandrasekaran are recipient of fellowship from the BK21 Programs by the Korea government (MEST). And this work was also supported by the Environmental Biotechnology National Core Research Center (20090091489) and Basic Science Research Program (2009-0073267) through the National Research Foundation of Korea (NRF) grant funded by MEST.

\section{References}

1. Franze de Fernandez, M. T.; Eoyang, L.; August, J. T. Nature
1968, 219, 588-590.

2. Sun, X.; Wartell, R. M. Biochemistry 2006, 45, 4875-4887.

3. Brennan, R. G.; Link, T. M. Curr. Opin. Microbiol. 2007, 10, 125133.

4. Lazar, P.; Kim, S.; Lee, Y.; Son, M.; Kim, H. H.; Kim, Y. S.; Lee, K. W. J. Mol. Graph. Mod. 2009, 28, 253-260.

5. Marlow, G. E.; Perkyns, J. S.; Pettitt, B. M. Chem. Rev. 1993, 93, 2503-2521.

6. de Haseth, P. L.; Uhlenbeck, O. C. Biochemistry 1980, 19(26), 6146-6151.

7. Lee, S. H. Bull. Korean Chem. Soc. 2009, 30(9), 2158-2160.

8. Lee, S. H. Bull. Korean Chem. Soc. 2006, 27(8), 1154-1158.

9. Oh, K. J.; Klein M. L. Bull. Korean Chem. Soc. 2009, 30(9), 20872092.

10. Berendsen, H. J. C.; van der Spoel, D.; van Drunen, R. Comp. Phys. Comm. 1995, 91, 43-56.

11. van der Spoel, D.; Lindahl, E.; Hess, B.; Groenhof, G.; Mark, A. E.; Berendsen, H. J. C. J. Comput. Chem. 2005, 26, 1701-1718.

12. Eric Sorin, J.; Vijay Pande, S. Biophys. J. 2005, 88, 2472-2493.

13. Jorgensen, W. L.; Chandrasekhar, J.; Madura, J. D.; Impey, R. W.; Klein, M. L. J. Chem. Phys. 1983, 79, 926-935.

14. Essman, U.; Perela, L.; Berkowitz, M. L.; Darden, T.; Lee, H.; Pedersen, L. G. J. Chem. Phys. 1995, 103, 8577-8592.

15. Berendsen, H. J. C.; Postma, J. P. M.; Di Nola, A.; Haak, J. R. J. Chem. Phys. 1984, 81, 3684-3690.

16. Parrinello, M.; Rahman, A. J. Appl. Phys. 1981, 52, 7182-7190.

17. Hess, B.; Bekker, H.; Berendsen, H. J. C.; Fraaije, J. G. E. M. J. Comp. Chem. 1997, 18, 1463-1472.

18. Ryckaert, J. P.; Ciccotti, G.; Berendsen, H. J. C. J. Comp. Phys. 1977, 23, 327-341.

19. Reynolds, C.; Damerell, D.; Jones, S. Bioinformatics 2009, 25 , 413-414.

20. Berman, H. M.; Westbrook, J.; Feng, Z.; Gilliland, G.; Bhat, T. N.; Weissig, H.; Shindyalov, I. N.; Bourne, P. E. Nucleic Acids Res. 2000, 28, 235-242. 